\title{
Reconeixement d'emocions en alumnat amb TEA: anàlisi de la literatura
}

Paula Bosch Collado - Universitat de València

Diana Marín Suelves - Universitat de València

Alba Tornero Cabedo - Universitat de València

(D) 0000-0002-5346-8665

Recepción: 03.10.2020 | Aceptado: 03.02.2021

Correspondencia a través de ORCID: Diana Marín Suelves

iD 0000-0002-5346-8665

Citar: Bosch Collado, P, Marín Suelves, D y Tornero Cabedo, A (2021). Reconeixement d'emocions en alumnat amb TEA: anàlisi de la literatura. REIDOCREA, 10(11), 1-18.

Resum: El present article presenta una revisió bibliogràfica mitjançant la qual es pretén conéixer l'efectivitat dels programes d'intervenció destinats a afavorir el reconeixement d'emocions en alumnat amb Trastorn de l'Espectre Autista. Per a la selecció d'articles es tingueren en compte una sèrie de criteris d'inclusió i d'exclusió, així s'examinaren 22 estudis en total. En la majoria dels estudis es mostren millores en el dèficit emocional analitzat i, de vegades, es destaca una disminució en els símptomes característics del trastorn. Considerant els resultats obtinguts es fica de manifest la necessitat de realitzar intervencions d'aquest tipus per contribuir a millorar la qualitat de vida d'aquestes persones.

Paraules clau: Trastorn del Espectre Autista

Development of emotion recognition in students with ASD. A bibliographical review

Abstract: This article is a bibliographical review through which the aim is to know the effectiveness of intervention programmes aimed at favouring the recognition of emotions in students with autism spectrum disorder. The selection of articles took into account a series of inclusion criteria and 22 studies in total were examined. In most studies, improvements in the emotional deficit analysed are shown and, sometimes, a decrease in the characteristic symptoms of the disorder is highlighted. Considering the results obtained, the need to carry out such interventions is revealed to help improve the quality of life of these people.

Keywords: Autism Spectrum Disorder

\section{Introducció}

Pel que fa a l'evolució del terme d'autisme, Bleuler empra per primera vegada la paraula "autisme" l'any 1911. L'autisme és una característica de les persones que tenen esquizofrènia, considerant una dificultat per comunicar-se i una tendència a romandre aïllats (Cuxart et al., 1998). Però, al llarg dels anys s'han produït modificacions arran un prolongat procés d'investigació. Així, es troben tres etapes explicatives per entendre l'evolució d'aquest concepte (Rivière, 2005):

En la primera etapa (1943-1963) s'assigna el terme autista a Kanner i es pensa que l'origen és una carència de contacte afectiu en els primers anys de vida que es manifesta en una alteració emocional que afecta la personalitat del subjecte que, finalment, deriva en l'adquisició d'aquest trastorn. Aquesta idea provoca la creença d'utilitzar tractament psicodinàmic.

En la segona etapa (1963-1983) es defineix l'autisme com un desordre neurobiològic. A partir d'aquest moment passa a considerar-se un trastorn del neurodesenvolupament i no un trastorn mental. A més a més, el tipus de tractament canvia per la nova hipòtesis que se sosté sobre una alteració cognitiva que explica les dificultats experimentades per aquestes persones. Aquest pensament se sustenta gràcies als bons resultats de les primeres aplicacions basades en principis conductuals, com són els treballs de Ferster i DeMeyer (Alcantud i Alonso, 2019). 
L'última etapa, que engloba des dels darrers anys fins a l'actualitat, se centra a comprendre el procés evolutiu per tal d'arribar a entendre millor la naturalesa del trastorn. Així, un tret característic d'aquesta etapa ha sigut el descobriment de la carència de la Teoria de la Ment.

Respecte a la tipologia diagnòstica, aquesta també ha anat canviant. Així, s'ha passat de referir-se a l'autisme com un tipus de reacció esquizofrènica infantil en el DSM-I, per exemple, fins a un Trastorn de l'Espectre Autista en el DSM-V.

Segons el DSM-V, en l'actualitat el TEA es defineix com un "trastorn del neurodesenvolupament d'origen neurobiològic i inici en la infància, que afecta el desenvolupament de la comunicació social, com de la conducta, com la presència de comportament i interessos repetitius i restringits" (Zuñiga et al., 2017, p.92). Dins d'aquest manual s'especifiquen tres nivells de gravetat que es relacionen amb el grau de suport que necessiten els xiquets.

En relació amb la prevalença de l'autisme, a partir dels darrers cinquanta anys, s'ha trobat una tendència a l'alça en relació amb els casos existents. Açò es deu als canvis que s'han produït en els criteris diagnòstics, a l'augment dels servicis d'atenció disponibles $\mathrm{i}$ als avanços relacionats amb la manera de detectar i diagnosticar el trastorn. Així, la prevalença actual del TEA es situa en 1/145 xiquets (Alcantud et al., 2018) i s'ha fixat una ràtio de 4'5:1 per sexe, indicant que és la població masculina qui més presenta el trastorn i que no es troben diferencies socials ni culturals entre zones geogràfiques (Sevilla et al., 2013).

Respecte a l'etiologia del trastorn, es pot afirmar que hui en dia no s'ha determinat. Tanmateix, els investigadors pensen que hi ha una relació entre factors genètics i ambientals.

Amb tot açò, a finals del segle $X X$ sorgeixen un conjunt de teories que intenten donar una explicació a l'autisme. Destaca la Teoria de la Ment (ToM), que és la que es relaciona amb el dèficit en la comunicació i interacció social que presenten les persones amb TEA. La ToM és una habilitat purament mental, és a dir, permet percebre estats mentals, propis i aliens, com desitjos, creences, intencions, emocions. Segons Lozano i Alcaraz (2012), aquest dèficit es tradueix, com a mínim, en limitats intents d'interacció, provocant un tracte cap a la resta de persones paregut al que es té amb qualsevol objecte inanimat, com poden ser els seus joguets.

La primera demostració relacionada amb l'alteració de la ToM per part dels TEA va aparèixer gràcies al treball realitzat per Baron-Cohen, Leslie i Frith (1985). En aquesta investigació es duen a terme diferents proves, en participants de desenvolupament normal, autistes i Síndrome de Down, per comprovar l'habilitat mentalista. Després d'haver-se realitzat i comprovat els resultats obtinguts, s'arriba a la conclusió que aquest dèficit és particular de l'autisme (Alcantud i Alonso, 2019). Aquest constructe psicològic abasta un conjunt de capacitats cognitives i, entre elles, el present informe se centra en el reconeixement d'emocions facials. D'aquesta manera, les persones autistes poden desenvolupar-se amb menor dificultat en aquelles tasques que no demanden de l'atribució emocional. Però, és important destacar que els autistes no són incommovibles, també ploren i riuen. No obstant això, tenen dificultats en respondre de forma correcta a estímuls visuals, com l'expressió facial, i auditius, com la veu. Aleshores, el fet que no puguen relacionar un rostre disgustat, amb una veu trista, un gest de tristesa i un escenari desagradable, per exemple, es relaciona amb problemes per comprendre les emocions, i aquest fet va molt lligat amb l'empatia, perquè són 
incapaços de mostrar-la. Per tant, dita afectació es tradueix en una dificultat per accedir al món emocional.

\section{Objectiu}

A partir d'aquesta informació, es pretén conèixer les intervencions que s'han realitzat els últims quinze anys, i que van dirigides al reconeixement i l'expressió de les emocions en xiquets que presenten aquest trastorn, així com saber com s'han dut a terme i quina ha sigut la seua eficàcia. A més a més, amb l'adquisició d'aquesta informació es pretén adquirir evidències científiques que possibiliten elaborar propostes d'intervencions futures amb certes garanties d'èxit.

\section{Mètodes}

La recerca dels articles inclosos en la present revisió bibliografia va tindre lloc en març de 2020 i, per a fer-ho, es van emprar un total de tres bases de dades: ERIC, Scopus i Redined.

En relació amb els objectius proposats, les paraules claus que es van introduir foren, utilitzant els operadors booleans OR i/o AND, Autism OR "autism spectrum disorder" AND intervention AND recognition AND emotions AND school OR learning OR education.

Amb la finalitat d'aconseguir una recerca més acurada, es tingueren en compte uns criteris d'inclusió i d'exclusió. Per una banda, els criteris d'inclusió són:

- Articles compresos entre 2005 i 2020.

- Idioma: castellà o anglés.

- Articles científics.

- Mostra dels participants formada amb persones diagnosticades amb TEA.

- L'edat dels participants ha d'estar dins del període d'escolarització obligatòria.

- Intervencions dirigides al reconeixement d'emocions.

Per altra banda, s'anomenen els d'exclusió:

- Articles repetits.

- No disponibilitat dels articles.

- No ser programa d'intervenció educativa.

- Ser una revisió bibliogràfica.

- No ser mostra amb TEA.

- Articles dirigits a joves i adults.

Amb aquests filtres s'obtingueren 6 articles n'ERIC, 19 en Scopus i 4 en Redined. Però, després de realitzar una lectura del contingut, s'ha reduït el nombre a 3 articles en ERIC, 11 en Scopus i 2 en Redined. Tanmateix, una vegada realitzada la lectura detallada d'aquests, s'ha fet una altra recerca, però a la inversa, seleccionant aquells articles que compleixen amb els criteris d'inclusió d'entre la bibliografia de cadascun dels articles seleccionats. Aleshores, el resultat final de la investigació ofereix un total de 22 articles.

En la Figura 1 es pot observar el procés seguit per a la recerca i per a l'obtenció del nombre d'articles finalment recopilats. 


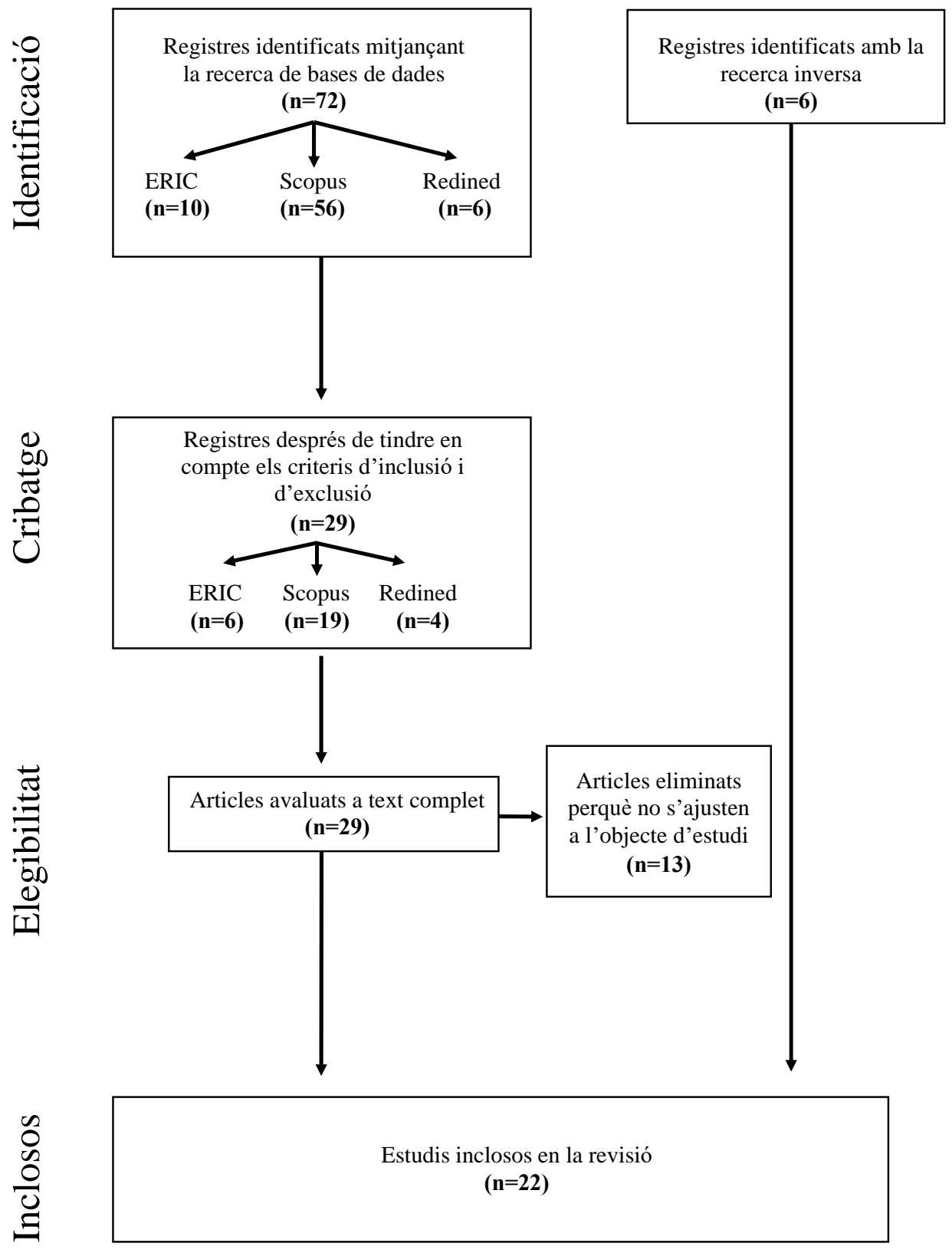

Figura 1. Diagrama de flux. Procés de selecció de documents per a l'anàlisi. 


\section{Resultats}

En la Taula 1 es presenta la informació clau dels articles analitzats referida a les dades d'identificació, els objectius i nombre d'emocions treballades, la mostra, els instruments, les característiques de la intervenció i els resultats aconseguits.

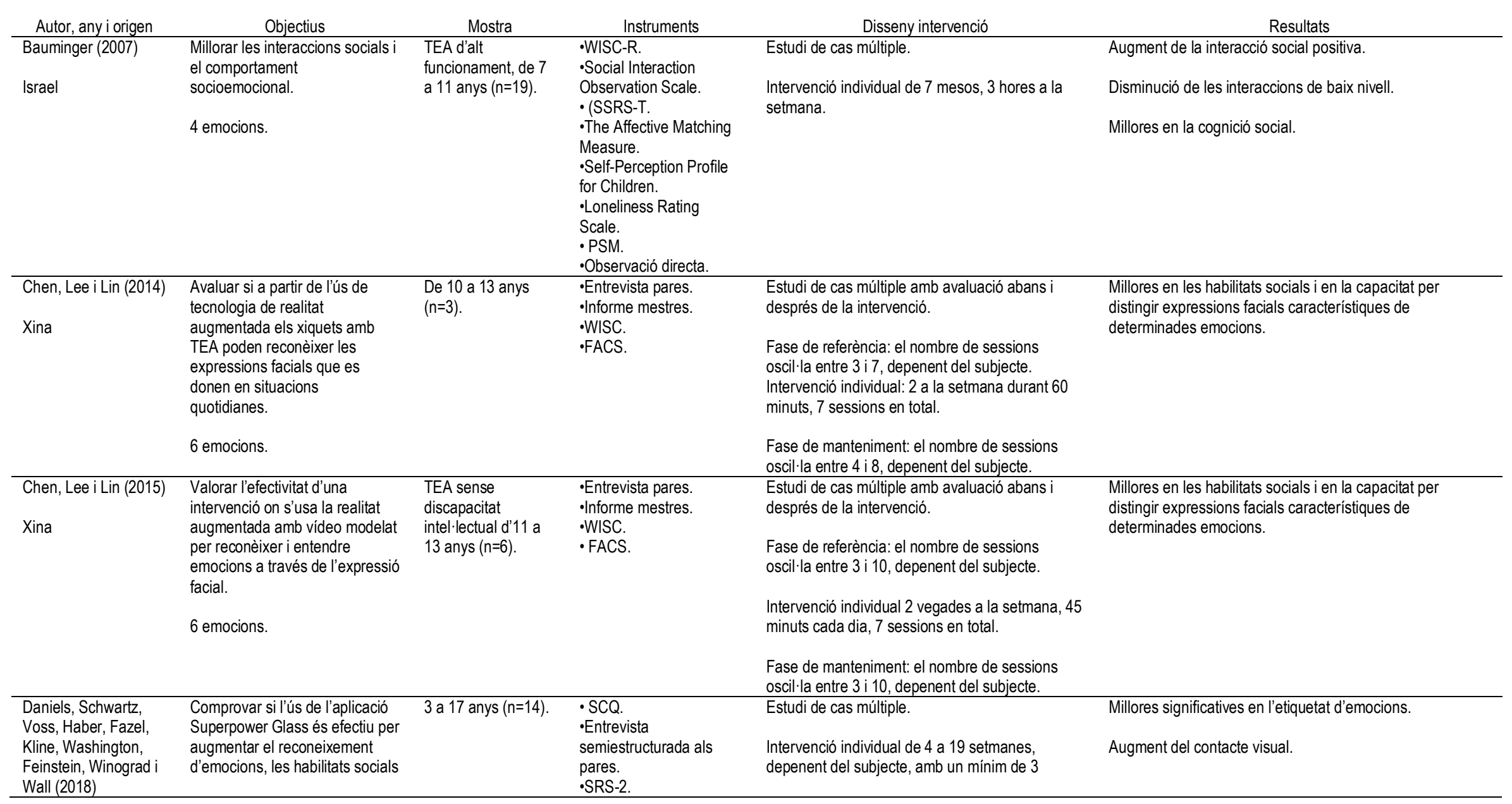




\begin{tabular}{|c|c|c|c|c|c|}
\hline EEUU & $\begin{array}{l}\text { i el contacte visual en xiquets } \\
\text { amb TEA. } \\
8 \text { emocions. }\end{array}$ & & $\begin{array}{l}\cdot \text { EGG. } \\
\cdot \text {-CBCL. } \\
\text {-MSCS. } \\
\text {-Vineland-II. } \\
\text {-SBIS. }\end{array}$ & $\begin{array}{l}\text { sessions de } 20 \text { minuts a la setmana (sense poder } \\
\text { realitzar més de } 2 \text { sessions al dia). }\end{array}$ & $\begin{array}{l}\text { Reducció significativa de les puntuacions de SRS-2 que } \\
\text { mesuren la gravetat del deteriorament social. }\end{array}$ \\
\hline $\begin{array}{l}\text { Fridenson-Hayo, } \\
\text { Berggren, Lassalle, } \\
\text { Tal, Pigat, Meir-Gore, } \\
\text { O'Reilly, Ben-Zur, } \\
\text { Bölte, Baron-Cohen i } \\
\text { Golan (2017) } \\
\text { Alemanya }\end{array}$ & $\begin{array}{l}\text { Examinar l'eficàcia d'un } \\
\text { programa amb caràcter } \\
\text { intercultural per a millorar el } \\
\text { reconeixement d'expressions } \\
\text { facials, llenguatge corporal, i } \\
\text { l'entonació vocal. } \\
10 \text { emocions. }\end{array}$ & $\begin{array}{l}\text { Fase } 1 \text { (Regne Unit, } \\
\text { n=15). } \\
\text { TEA amb Coeficient } \\
\text { Intel·lectual normal, } \\
\text { de } 6 \text { a } 9 \text { anys. } \\
\text { Fase } 2 \\
\text { TEA d'alt } \\
\text { funcionament, de } 6 \\
\text { a } 9 \text { anys. } \\
\text { Israel, } n=38 \\
G I n=18 \\
G C n=20 \\
\text { Suècia } n=36 \\
G I n=16 \\
G C n=20\end{array}$ & $\begin{array}{l}\text {-WISC-IV. } \\
\text {-WPPSI-3. } \\
\text {-SRS-2. } \\
\text {-VABS-II. } \\
\text {-ADOS-2 }\end{array}$ & $\begin{array}{l}\text { Regne Unit: } \\
\text { Estudi de cas múltiple. } \\
\text { Avaluació abans i després de la intervenció. } \\
\text { Intervenció individual de } 8 \text { setmanes. Ús del } \\
\text { programa, mínim, } 2 \mathrm{~h} \text { a la setmana. } \\
\text { Israel y Suècia: } \\
\text { Estudi de dos grups amb assignació aleatòria } \\
\text { (Assaig Controlat Aleatoritzat). } \\
\text { Avaluació abans i després de la intervenció. } \\
\text { Intervenció individual de } 8 \text { setmanes en Suècia i } \\
12 \text { setmanes en Israel. Ús de } 2 \mathrm{~h} \text { a la setmana del } \\
\text { programa. }\end{array}$ & $\begin{array}{l}\text { Regne Unit: } \\
\text { Millores en les tasques destinades a treballar el llenguatge } \\
\text { corporal del reconeixement d'emocions. } \\
\text { Israel y Suècia: Millores significatives en totes les tasques } \\
\text { del programa (cara, veu, llenguatge corporal i integració). }\end{array}$ \\
\hline $\begin{array}{l}\text { Golan, Ashwin, } \\
\text { Granader, McClintock, } \\
\text { Day, Leggett i Baron- } \\
\text { Cohe (2010) } \\
\text { Regne Unit }\end{array}$ & $\begin{array}{l}\text { Comprovar l'efectivitat de The } \\
\text { Transporters per a millorar la } \\
\text { comprensió i el reconeixement } \\
\text { d'emocions junt amb la } \\
\text { supervisió dels pares. } \\
15 \text { emocions. }\end{array}$ & $\begin{array}{l}\text { TEA d'alt } \\
\text { funcionament, de } 4 \\
\text { a anys. } \\
\text { Grup intervenció=20 } \\
\text { Grup control } \\
\text { (subjectes amb } \\
\text { desenvolupament } \\
\text { típic) } n=18 . \\
\text { Grup control: } \\
\text { (subjectes amb } \\
\text { TEA) } n=19 .\end{array}$ & $\begin{array}{l}- \text { ADI-R. } \\
\text { - CATS. } \\
\text { - BPVS. }\end{array}$ & $\begin{array}{l}\text { Estudi de dos grups amb assignació aleatòria } \\
\text { (Assaig Controlat Aleatoritzat). } \\
\text { Visionat de, almenys, } 3 \text { episodis de } 5 \text { minuts } \\
\text { cadascun al dia, durant } 4 \text { setmanes. }\end{array}$ & $\begin{array}{l}\text { Millores en les proves dels } 4 \text { nivells de reconeixement } \mathrm{i} \\
\text { comprensió de les } 15 \text { emocions presentades. Per tant, } \\
\text { s'aconsegueix la generalització del contingut més enllà del } \\
\text { materials proporcionat. } \\
\text { No es troben canvis significatius en cap dels grups control. }\end{array}$ \\
\hline $\begin{array}{l}\text { Hopkins, Gower, } \\
\text { Perez, Smith, Amthor, } \\
\text { Wimsatt i Biasini } \\
\text { (2011) } \\
\text { EEUU }\end{array}$ & $\begin{array}{l}\text { Avaluar l'eficàcia de FaceSay } \\
\text { per ensenyar habilitats de } \\
\text { reconeixement emocional i } \\
\text { facial. } \\
6 \text { emocions. }\end{array}$ & $\begin{array}{l}\text { TEA d'alt i baix } \\
\text { funcionament de } 6 \text { a } \\
15 \text { anys ( } n=48) \text {. } \\
\text { Baix funcionament } \\
\text { GI } n=11 \\
\text { GC } n=13 \\
\text { Alt funcionament } \\
\text { GI } n=13 \\
G C n=11\end{array}$ & $\begin{array}{l}\text { - CARS. } \\
\text {-KBIT-II. } \\
\text {-Emotion Recognition } \\
\text { from Ekman and } \\
\text { Friesen's photos. } \\
\text { - Benton Facial } \\
\text { Recognition Test. } \\
\text { - SSRS. } \\
\text {-Observació directa. }\end{array}$ & $\begin{array}{l}\text { Estudi de dos grups amb assignació aleatòria } \\
\text { (Assaig Controlat Aleatoritzat). } \\
2 \text { vegades per setmana, } 10-25 \text { minuts cada } \\
\text { sessió, durant } 6 \text { setmanes (12 sessions en total). }\end{array}$ & $\begin{array}{l}\text { Els xiquets amb baix funcionament s'enriquiren } \\
\text { especialment en dos àrees: reconeixement d'emocions i } \\
\text { interaccions socials. } \\
\text { Els xiquets amb alt funcionament milloraren en les tres } \\
\text { àrees: reconeixement d'emocions, reconeixement facial i } \\
\text { interaccions socials. }\end{array}$ \\
\hline $\begin{array}{l}\text { Lacava, Golan, } \\
\text { Baron-Cohen, i Smith } \\
\text { (2007) }\end{array}$ & $\begin{array}{l}\text { Validar l'ús de MindReading per } \\
\text { millorar el reconeixement } \\
\text { d'emocions facials i vocals. }\end{array}$ & 8 a 11 anys $(n=8)$ & $\begin{array}{l}- \text { - CAM-C. } \\
\text { - C-FAT. } \\
\text { - RMF-C. }\end{array}$ & Estudi pilot.: Estudi de cas múltiple. & $\begin{array}{l}\text { Millores en el reconeixement d'emocions, de rostres i veus, } \\
\text { bàsiques i complexes. }\end{array}$ \\
\hline
\end{tabular}




\begin{tabular}{|c|c|c|c|c|c|}
\hline EEUU & 15 emocions. & & & $\begin{array}{l}\text { Avaluació abans, durant i després de la } \\
\text { intervenció. } \\
\text { Intervenció individual durant un màxim de } 10 \\
\text { setmanes, amb un ús mitjà de } 10^{\prime} 5 \mathrm{~h} \text { del } \\
\text { programa. }\end{array}$ & \\
\hline $\begin{array}{l}\text { Lacava, Rankin, } \\
\text { Mahlios, Cook i } \\
\text { Simpson (2010) } \\
\text { EEUU }\end{array}$ & $\begin{array}{l}\text { Investigar l'eficàcia de } \\
\text { MindReading per a ensenyar } \\
\text { emocions i reconèixer estats } \\
\text { mentals, així com saber si la } \\
\text { lectura mental produeix millores } \\
\text { en les interaccions socials. } \\
15 \text { emocions. }\end{array}$ & $\begin{array}{l}\text { TEA sense } \\
\text { discapacitat } \\
\text { cognitiva, de } 7 \text { a } 11 \\
\text { anys }(n=4) \text {. }\end{array}$ & $\begin{array}{l}\text { - CAM-C. } \\
\text {-The color photos from } \\
\text { the Mind Reading } \\
\text { Library. } \\
\text { - Observació directa. }\end{array}$ & $\begin{array}{l}\text { Estudi de cas múltiple. } \\
\text { Intervenció individual de } 7 \text { a } 10 \text { setmanes, durant } \\
102 \text { hores setmanals. }\end{array}$ & $\begin{array}{l}\text { Els quatre participants milloraren en les proves de cara y } \\
\text { solament tres en les proves de veu. } \\
\text { No millores significatives en la interacció social positiva. }\end{array}$ \\
\hline $\begin{array}{l}\text { Lopata, Thomeer, } \\
\text { Volker, Toomey, Nida, } \\
\text { Lee, Smerbeck i } \\
\text { Rodgers (2010) } \\
\text { EEUU }\end{array}$ & $\begin{array}{l}\text { Comprovar l'efectivitat d'una } \\
\text { intervenció destinada a millorar } \\
\text { habilitats socials, la interpretació } \\
\text { del llenguatge no literal, } \\
\text { l'expansió d'interessos i el } \\
\text { reconeixement d'emocions } \\
\text { facials. }\end{array}$ & $\begin{array}{l}\text { TEA d'alt } \\
\text { funcionament, de } 7 \\
\text { a } 12 \text { anys }(n=36) \text {. } \\
\text { GI n=18. } \\
\text { GC } n=18 \text {. }\end{array}$ & $\begin{array}{l}\text {-WISC-IV. } \\
\cdot \text { CASL4. } \\
\text {-ASC } \\
\text { - SRS } \\
\text {-BASC-2 per pares i } \\
\text { mestres. } \\
\text {-SKA. } \\
\text {-DANVA2. }\end{array}$ & $\begin{array}{l}\text { Estudi de dos grups amb assignació aleatòria } \\
\text { (Assaig Controlat Aleatoritzat). } \\
70 \text { minuts al dia ( } 20 \text { min d'instrucció directa i } 50 \\
\text { min d'activitat terapèutica) durant } 6 \text { setmanes. } \\
\text { Però, per al reconeixement d'emocions solament } \\
\text { es van dedicar } 6 \text { sessions de } 20 \text { minuts. }\end{array}$ & $\begin{array}{l}\text { Disminució dels simptomes de TEA. } \\
\text { Millores significatives en habilitats socials. } \\
\text { Les millores en el reconeixement d'emocions no són } \\
\text { significatives. }\end{array}$ \\
\hline $\begin{array}{l}\text { Lozano i Alcaraz } \\
\text { (2011) } \\
\text { Espanya }\end{array}$ & $\begin{array}{l}\text { Conèixer l'impacte d'un software } \\
\text { per a millorar les habilitats } \\
\text { emocionals en xiquets amb } \\
\text { TEA. } \\
8 \text { emocions. }\end{array}$ & 10 a 15 anys $(n=4)$. & $\begin{array}{l}\text {-Aprende con Zapo. } \\
\text { Propuestas didácticas } \\
\text { para el aprendizaje de } \\
\text { habilidades emocionales } \\
\text { y sociales. } \\
\text {-Entrevistes als docents i } \\
\text { als pares. } \\
\text {-Diari personal de l'equip } \\
\text { de treball. }\end{array}$ & $\begin{array}{l}\text { Estudi de cas múltiple. } \\
\text { Avaluació abans i després de la intervenció. } \\
\text { Intervenció individual durant } 10 \text { setmanes. No } \\
\text { s'especifica el temps d'ús diari. }\end{array}$ & $\begin{array}{l}\text { Millores en la interacció social i en la capacitat per } \\
\text { identificar, reconèixer i comprendre emocions. }\end{array}$ \\
\hline $\begin{array}{l}\text { Lozano i Alcaraz } \\
\text { (2012) } \\
\text { Espanya }\end{array}$ & $\begin{array}{l}\text { Ensenyar l'enteniment de les } \\
\text { emocions i les creences } \\
\text { mitjançant l'ús de materials } \\
\text { didàctics i valorar l'efecte de la } \\
\text { intervenció sobre les habilitats } \\
\text { socials dels subjectes. } \\
4 \text { emocions. } \\
\end{array}$ & 8 a 14 anys $(n=3)$. & $\begin{array}{l}\text { - KBIT. } \\
\text {-Observació directa. } \\
\text {-Entrevista } \\
\text { semiestructurada al } \\
\text { docent. } \\
\text { •Entrevista als pares. }\end{array}$ & $\begin{array}{l}\text { Estudi de cas múltiple. } \\
\text { Avaluació abans i després de la intervenció (1 } \\
\text { sessió de } 45 \text { minuts). } \\
\text { Intervenció individual durant } 11 \text { setmanes, } 2 \\
\text { sessions a la setmana de } 30 \text { minuts cadascuna. }\end{array}$ & $\begin{array}{l}\text { Encara que hi ha millores relacionades amb els objectius } \\
\text { perseguits, es destaca una milloria lenta i no molt } \\
\text { pronunciada. }\end{array}$ \\
\hline $\begin{array}{l}\text { Lopata, Thomeer, } \\
\text { Rodgers, Donelly, } \\
\text { Volker, Smith, } \\
\text { McDonald i Wang } \\
\text { (2019) } \\
\text { EEUU }\end{array}$ & $\begin{array}{l}\text { Comprovar els efectes d'un } \\
\text { programa d'intervenció integral } \\
\text { basat en l'escola per millorar } \\
\text { habilitats socials i } \\
\text { reconeixement d'emocions. }\end{array}$ & $\begin{array}{l}\text { TEA d'alt } \\
\text { funcionament, de } 6 \\
\text { a } 9 \text { anys }(n=102) \text {. } \\
\text { GI n=52. } \\
\text { GC } n=50 \text {. }\end{array}$ & $\begin{array}{l}\text {-WISC-IV. } \\
\text {-CAM-C. } \\
\text {-ADI-R. } \\
\text { - CASL. } \\
\text {-SRS-2. } \\
\text { - ASC. } \\
\text { - SIOS. }\end{array}$ & $\begin{array}{l}\text { Estudi de dos grups amb assignació aleatòria } \\
\text { (Assaig Controlat Aleatoritzat). } \\
10 \text { setmanes de duració, on es treballen habilitats } \\
\text { socials ( } 2 \text { o } 3 \text { vegades per setmana durant } 60-90 \\
\text { min per alumne), activitats terapèutiques ( } 2 \\
\text { vegades per setmana durant } 40-60 \text { minuts per }\end{array}$ & $\begin{array}{l}\text { Progressos significatius en el reconeixement d'emocions } \\
\text { facials i vocals i en les competències socials. } \\
\text { Disminució dels simptomes del TEA. } \\
\text { No hi ha millores en les interaccions socials. }\end{array}$ \\
\hline
\end{tabular}




\begin{tabular}{|c|c|c|c|c|c|}
\hline & & & -WJ-III Ach. & $\begin{array}{l}\text { alumne), reconeixement d'emocions facials y } \\
\text { vocals ( } 2 \text { vegades per setmana durant } 60 \text { minuts } \\
\text { per alumne) i entrenament per a pares ( } 1 \text { vegada } \\
\text { al mes durant } 60-90 \text { minuts). }\end{array}$ & \\
\hline $\begin{array}{l}\text { McHugh, Bobarnac i } \\
\text { Reed (2010) } \\
\text { Regne Unit }\end{array}$ & $\begin{array}{l}\text { Ensenyar a reconèixer i a } \\
\text { etiquetar } 4 \text { emocions bàsiques i } \\
\text { comprovar la generalització de } \\
\text { l'aprenentatge usant estímuls } \\
\text { diferents. } \\
4 \text { emocions. }\end{array}$ & $\begin{array}{l}\text { TEA de } 5 \text { anys } \\
(n=3) .\end{array}$ & - Clips de vídeo. & $\begin{array}{l}\text { Estudi de cas múltiple. } \\
10 \text { sessions al dia en diferents moment, } \\
\text { cadascuna de } 2-5 \text { minuts, durant } 6 \text { dies. }\end{array}$ & $\begin{array}{l}\text { S'aconsegueix l'etiquetat de les emocions treballades i la } \\
\text { seua generalització. }\end{array}$ \\
\hline $\begin{array}{l}\text { Ryan i Charragaín } \\
\text { (2010) } \\
\text { Irlanda }\end{array}$ & $\begin{array}{l}\text { Ensenyar a reconèixer } \\
\text { emocions focalitzant l'atenció en } \\
\text { cadascuna de les parts de la } \\
\text { cara. } \\
6 \text { emocions. }\end{array}$ & $\begin{array}{l}\text { TEA d'alt } \\
\text { funcionament, de } 6 \\
\text { a } 14 \text { anys }(n=30) \text {. } \\
\text { GI } n=20 \text {. } \\
\text { GC } n=10 \text {. }\end{array}$ & $\begin{array}{l}\text {-ADOS. } \\
\text { - PPVT-R. } \\
\text { - CARS. } \\
\text {-ERT. } \\
\text {-Emotion Vocabulary } \\
\text { Comprehension Test. }\end{array}$ & $\begin{array}{l}\text { Estudi de dos grups amb assignació aleatòria } \\
\text { (Assaig Controlat Aleatoritzat). } \\
\text { Una sessió a la setmana d'1h, durant } 4 \\
\text { setmanes. }\end{array}$ & $\begin{array}{l}\text { Avanços significatius en comparació amb el grup control, } \\
\text { relacionats amb l'etiquetat d'emocions i situacions en les } \\
\text { que aquestes apareixen. }\end{array}$ \\
\hline $\begin{array}{l}\text { Russo-Ponsaran, } \\
\text { Evans-Smith, } \\
\text { Johnson i McKown } \\
\text { (2014) } \\
\text { EEUU }\end{array}$ & $\begin{array}{l}\text { Comprovar el grau d'acceptació } \\
\text { i viabilitat de MiX, destinat a } \\
\text { augmentar l'atenció i la velocitat } \\
\text { en el reconeixement d'emocions } \\
\text { facials. } \\
7 \text { emocions. }\end{array}$ & 9 a 11 anys $(n=3)$ & $\begin{array}{l}\text { - SCQ. } \\
\text { - WASI. } \\
\text { - ADOS. } \\
\text { - CATS. } \\
\text { - DANVA. }\end{array}$ & $\begin{array}{l}\text { Estudi pilot: Estudi de cas múltiple. } \\
\text { Avaluació abans, durant i després de la } \\
\text { intervenció. } \\
\text { Intervenció individual durant un màxim de } 8 \\
\text { setmanes, } 2 \text { sessions a la setmana d'una hora } \\
\text { cadascuna (màxim } 16 \text { sessions). }\end{array}$ & $\begin{array}{l}\text { Es va completar el programa en menys d'11 sessions. Els } \\
\text { tres mostraren millores en el reconeixement d'emocions } \\
\text { facials. Però, a la prova de manteniment els resultats } \\
\text { baixaren, encara que continuaven per damunt dels } \\
\text { obtinguts a la prova de preentrenament. }\end{array}$ \\
\hline $\begin{array}{l}\text { Russo-Ponsaran, } \\
\text { Smith, Johnson, } \\
\text { Russo i McKown } \\
\text { (2015) } \\
\text { EEUU }\end{array}$ & $\begin{array}{l}\text { Valorar l'efectivitat d'un } \\
\text { entrenament dirigit a millorar el } \\
\text { reconeixement d'emocions } \\
\text { facials i l'autoexpressió. } \\
6 \text { emocions. }\end{array}$ & $\begin{array}{l}\text { TEA d'alt } \\
\text { funcionament, de } 8 \\
\text { a } 15 \text { anys }(n=25) . \\
\text { GI n=12 } \\
\text { GC n=13. }\end{array}$ & $\begin{array}{l}\text { - SCQ. } \\
\text {-ADOS. } \\
\text {-ADI-R. } \\
\text {-WASI-2. } \\
\text {-WISC-IV. } \\
\text { - CATS. } \\
\text {-DANVA. } \\
\text {-NEPSY-II } \\
\text { - BarOn EQl:YV. } \\
\text { - EDI-C. } \\
\text { - Gravacions de vídeo. }\end{array}$ & $\begin{array}{l}\text { Estudi de dos grups amb assignació aleatòria } \\
\text { (Assaig Controlat Aleatoritzat). } \\
\text { Dos vegades a la setmana, } 60 \text { minuts cada } \\
\text { sessió, durant } 8 \text { setmanes ( } 16 \text { sessions en total). }\end{array}$ & $\begin{array}{l}\text { Millores significatives en les proves de reconeixement } \\
\text { d'afectes. } \\
\text { Millores significatives en l'expressió del menyspreu, ira, } \\
\text { disgust i sorpresa. La por no va ser significativa. L'alegria i } \\
\text { la tristesa tampoc ja que partien d'un nivell prou elevat. } \\
\text { Millores en la imitació de la ira, disgust, sorpresa i } \\
\text { menyspreu. } \\
\text { No se destaquen millores en la prova de vocabulari } \\
\text { emocional. }\end{array}$ \\
\hline $\begin{array}{l}\text { Rice, Wall, Fogel i } \\
\text { Shic (2015) } \\
\text { EEUU }\end{array}$ & $\begin{array}{l}\text { Augmentar els resultats } \\
\text { relacionats amb l'eficàcia de } \\
\text { FaceSay per millorar el } \\
\text { reconeixement d'emocions, la } \\
\text { mentalització i les habilitats } \\
\text { socials. } \\
6 \text { emocions. }\end{array}$ & $\begin{array}{l}\text { TEA d'alt } \\
\text { funcionament, de } 5 \\
\text { a } 11 \text { anys }(n=31) \text {. } \\
\text { GI } n=16 \text {. } \\
\text { GC } n=15 \text {. }\end{array}$ & $\begin{array}{l}\cdot \text {-WISC-III i WISC-IV. } \\
\text {-NEPSY-II. } \\
\text {-NEPSY-II. } \\
\text {-SRS-2. }\end{array}$ & $\begin{array}{l}\text { Estudi de dos grups amb assignació aleatòria } \\
\text { (Assaig Controlat Aleatoritzat). } \\
\text { Una vegada a la setmana, } 25 \text { minuts per sessió, } \\
\text { durant } 10 \text { setmanes ( } 10 \text { sessions en total). }\end{array}$ & $\begin{array}{l}\text { Millores en l'habilitat per reconèixer emocions i mentalitzar. } \\
\text { Però, no hi ha diferències significatives en les interaccions } \\
\text { socials positives i negatives. }\end{array}$ \\
\hline
\end{tabular}




\begin{tabular}{|c|c|c|c|c|c|}
\hline $\begin{array}{l}\text { Thomeer, Smith, } \\
\text { Lopata, Volker, } \\
\text { Lipinski, Rodgers, } \\
\text { McDonald i Lee } \\
\text { (2015) } \\
\text { EEUU }\end{array}$ & $\begin{array}{l}\text { Avaluar l'efectivitat d'un } \\
\text { programa informàtic combinat } \\
\text { amb instrucció en directe, dirigit } \\
\text { a ensenyar el reconeixement } \\
\text { d'emocions, millorar les } \\
\text { habilitats socials i disminuir els } \\
\text { símptomes del TEA. } \\
15 \text { emocions. }\end{array}$ & $\begin{array}{l}\text { TEA d'alt } \\
\text { funcionament, de } 7 \\
\text { a } 12 \text { anys }(n=43) \text {. } \\
\text { GI } n=22 \\
\text { GC } n=21\end{array}$ & $\begin{array}{l}\text {-WISC-IV. } \\
\text {-CASL. } \\
\text {-ADI-R. } \\
\text {-CAM-C. } \\
\text { •SRS. } \\
\text {-BASC-2. }\end{array}$ & $\begin{array}{l}\text { Estudi de dos grups amb assignació aleatòria } \\
\text { (Assaig Controlat Aleatoritzat). } \\
2 \text { sessions de } 90 \text { minuts a la setmana durant } 12 \\
\text { setmanes ( } 24 \text { sessions). }\end{array}$ & $\begin{array}{l}\text { Diferències significatives en el reconeixement d'emocions } \\
\text { en comparació amb el grup control. } \\
\text { Les habilitats socials eren més altes, encara que no foren } \\
\text { millores significatives. } \\
\text { Disminució símptomes TEA. }\end{array}$ \\
\hline $\begin{array}{l}\text { Williams, Gray i } \\
\text { Tonge (2012) } \\
\text { EEUU }\end{array}$ & $\begin{array}{l}\text { Avaluar l'efectivitat de l'ús de } \\
\text { The Transporters DVD sobre el } \\
\text { reconeixement d'emocions i } \\
\text { comprovar si els resultats es } \\
\text { tradueixen en millores en les } \\
\text { habilitats socials i en la Teoria } \\
\text { de la Ment. } \\
15 \text { emocions. }\end{array}$ & $\begin{array}{l}4 \text { a } 7 \text { anys }(n=55) \text {. } \\
\text { GI } n=28 \text {. } \\
\text { GC } n=27 .\end{array}$ & $\begin{array}{l}\text {-WPPSI-III. } \\
\text {-The Socialization } \\
\text { Domain of the Vineland-II } \\
\text { survey form. } \\
\text { •ADOS. } \\
\text { •Emotion identification } \\
\text { and emotion matching } \\
\text { tasks. } \\
\text {-Emotion identification } \\
\text { and emotion matching } \\
\text { tasks. }\end{array}$ & $\begin{array}{l}\text { Estudi de dos grups amb assignació aleatòria } \\
\text { (Assaig Controlat Aleatoritzat). } \\
15 \text { minuts al dia ( } 3 \text { capítols) durant } 4 \text { setmanes. }\end{array}$ & $\begin{array}{l}\text { Després de la intervenció es mostren millores en la } \\
\text { identificació solament de la ira, però al cap de } 3 \text { mesos } \\
\text { aquesta habilitat va disminuir. } \\
\text { En el reconeixement d'altres emocions no es produïren } \\
\text { resultats. }\end{array}$ \\
\hline $\begin{array}{l}\text { Young i Posselt } \\
\text { (2011) } \\
\text { Austràlia }\end{array}$ & $\begin{array}{l}\text { Comprovar la millora en el } \\
\text { reconeixement i comprensió } \\
\text { d'emocions, i altres habilitats } \\
\text { socials, a partir del visionat del } \\
\text { DVD The Transporters. } \\
15 \text { emocions. }\end{array}$ & $\begin{array}{l}4 \text { a } 8 \text { anys }(n=25) \text {. } \\
G I n=13 . \\
G C n=12 .\end{array}$ & $\begin{array}{l}\cdot \text {-WPPSI-III. } \\
\text {-WISC-IV } \\
\text {-NEPSY-II } \\
\cdot \text {-SCQ. }\end{array}$ & $\begin{array}{l}\text { Estudi de dos grups amb assignació aleatòria } \\
\text { (Assaig Controlat Aleatoritzat). } \\
\text { Veure, com a mínim, } 3 \text { episodis al dia durant } 3 \\
\text { setmanes. Cadascun té una duració de } 5 \text { a } 10 \\
\text { minuts i hi ha } 15 \text { capítols en total. }\end{array}$ & $\begin{array}{l}\text { Per una banda, millores en el reconeixement d'emocions } \\
\text { del grup d'intervenció. Per altra banda, millores en el } \\
\text { comportament social i el contacte visual en els dos grups, } \\
\text { per tant, es milloraren habilitats socials que no estaven } \\
\text { previstes. }\end{array}$ \\
\hline $\begin{array}{l}\text { Zhang, Xia, Li, Shen, } \\
\text { Liu, Zhao i Chen } \\
\text { (2019) } \\
\text { Xina }\end{array}$ & $\begin{array}{l}\text { Valorar l'efectivitat i viabilitat } \\
\text { d'una aplicació informàtica, } \\
\text { Qunatiandi, per a millorar el } \\
\text { reconeixement facial d'emocions } \\
\text { i la comprensió d'aquestes en } \\
\text { diferents situacions o contextos. } \\
13 \text { emocions. }\end{array}$ & 3 a 6 anys $(n=3)$. & $\begin{array}{l}\text {-PEP-3. } \\
\text {-Qunatiandi. }\end{array}$ & $\begin{array}{l}\text { Estudi de cas. } \\
\text { Intervenció individual, } 5 \text { vegades a la setmana, } \\
45 \text { minuts al dia ( } 15 \text { minuts cada fase: ensenyar, } \\
\text { distingir i comprendre) durant } 8 \text { setmanes. }\end{array}$ & $\begin{array}{l}\text { Avanços significatius en la distinció i comprensió } \\
\text { d'emocions. } \\
\text { Resultats positius en el manteniment. }\end{array}$ \\
\hline
\end{tabular}




\section{Discussió}

Borra y escribe en esta sección los aspectos novedosos y relevantes del trabajo. Hay que evitar repetir, con detalle, la información o datos ya presentados en las secciones anteriores. Se comentarán los resultados obtenidos con relación a otros estudios realizados previamente, interpretando diferencias y similitudes. Deben señalarse las fortalezas y limitaciones del estudio, comentando e interpretando los resultados. En este apartado se incluirán las conclusiones que deben de relacionarse con los objetivos del estudio, evitando afirmaciones no respaldadas por los datos obtenidos.

A continuació es realitza una anàlisi de variables estructurals i de contingut. Quant a les variables estructurals s'analitza el nombre d'autors, el país i la data de publicació dels articles.

Destaca que totes, excepte la de Bauminger (2007), han sigut realitzades en $\mathrm{col} \cdot$ laboració. A més a més, s'identifiquen alguns autors de referència en aquest camp d'estudi, ja que han publicat diversos articles centrats en aquesta temàtica, com ara, Lozano, Alcaraz, Russo-Ponsaran, Chen, Lopata, Thomeer, Volker i Rodgers. Encara que hi ha més homes que dones (25\%), es valora la representació d'aquestes en els últims anys, la qual cosa és positiva des d'una perspectiva de gènere.

Amb relació al lloc de la publicació, s'han realitzat intervencions fins en quatre continents (Oceania, Àsia, Europa i Amèrica). S'ha fet una a Oceania, concretament a Austràlia (Young i Posselt, 2011), també a Àsia, en la Xina (Chen et al., 2015; Chen et al., 2016; Zhang et al., 2019), seguidament se situa Europa, on s'han dut a terme en Espanya (Lozano i Alcaraz, 2011; Lozano i Alcaraz, 2012), Alemanya (Fridenson-Hayo et al., 2017), Irlanda (Ryan i Charragaín, 2010), Israel (Bauminger, 2007) i Regne Unit (Golan et al., 2010; McHugh et al., 2010). La resta dels treballs, i el que més predomina amb un $50 \%$, s'ha realitzat en el continent americà, concretament en EEUU.

Pel que fa a l'any de la publicació es pot observar un increment en les intervencions relacionades amb el dèficit analitzat. Així, sols es troba el treball de Bauminger (2007) i Lacava et al. (2007). Però, justament és l'any 2010 quan es produeix una tendència creixent en la publicació d'articles (Lopata et al., 2010; Lacava et al., 2010; Golan et al., 2010; Ryan i Charragaín 2010; McHugh et al., 2010). A partir del 2011 fins al 2015 el percentatge de publicacions (45'45\%), ha estat prou elevat en comparació a la resta (Lozano i Alcaraz 2011; Hopkins et al., 2011; Young i Posselt, 2011; Lozano i Alcaraz, 2012; Williams et al., 2012; Russo-Ponsaran et al., 2014; Rice et al., 2015; Chen et al., 2015; Russo-Ponsaran et al., 2015, Thomeer et al., 2015). Finalment, la franja d'anys que van des del 2016 fins al 2020, ens diu que la corba de publicacions s'ha mantingut baixa però estable, entre 0 i 2 publicacions per any (Chen et al., 2016; Fridenson-Hayo et al., 2017; Daniels et al., 2018; Lopata et al., 2019; Zhang et al., 2019).

Les variables de contingut analitzades van ser la mostra, la metodologia (tipus d'estudis, espais d'intervenció, recursos, instruments i durada de les intervencions) i resultats.

Pel que fa al nombre de participants dels estudis analitzats, no tots segueixen la mateixa línia i hi ha casos on les diferències arriben a ser considerables. Per una banda, es troben els treballs que no inclouen grup control. Així, el 31 ' $8 \%$ dels estudis se situen en un màxim de fins a 5 subjectes (Lacava et al., 2010; McHugh et al., 2010; Lozano i Alcaraz, 2011; Lozano i Alcaraz, 2012; Chen et al., 2016; Russo-Ponsaran et al., 2014; Zhang et al., 2019). Seguits dels 6 participants en Chen et al. (2015) i dels 8 participants en Lacava et al. (2007). Tenint estudis amb una mostra menor de 10 participants 
(40'88\%). Per últim, s'engloben aquells que estan dins de la franja dels 11 als 20 subjectes, com són el de Daniels et al. (2018) amb 14 i Bauminger (2007) amb 19.

Per altra banda, s'agrupen els articles que inclouen grup control. En primer lloc, Young i Posselt (2011) i Russo-Ponsaran et al. (2015), tenen un total de 25 nens, dels quals 13 han realitzat la intervenció i 12 corresponen al grup control. En segon lloc es situen Ryan i Charragaín (2010) amb 30 participants, 20 al grup d'intervenció; seguits de Rice et al. (2015) amb 31, però solament 16 reben el tractament. En tercer lloc, se situa Lopata et al. (2010) amb 36 subjectes dividits formant dos grups de 18 en cadascun. A continuació, Thomeer et al. (2015) amb una mostra de 43, dels quals 22 són grup d'intervenció. Seguidament, en Hopkins et al. (2011) hi ha una intervenció de 48 membres dividida en dos grups d'intervenció i dos grups control, d'entre 11 i 13 subjectes cadascun, segons si són TEA dalt o baix funcionament. Per últim, hi ha dos articles amb més de 50 membres, per una banda, Williams et al. (2012) que compta amb 55 participants, dels quals 28 es troben al grup d'intervenció, i Lopata et al. (2019) que té 102 participants, amb 52 membres al grup d'intervenció.

Cal mencionar tant el treball de Golan et al. (2010) com el de Fridenson-Hayo et al. (2017). El primer es caracteritza per tindre 58 participants dividits en tres grups, un d'intervenció amb 25 membres i dos controls; un format per 24 xiquets amb desenvolupament neurotípic i l'altre per 19 xiquets amb TEA. En el segon article tractem tres intervencions realitzades en diferents països. D'aquestes tres intervencions són dos amb grups control en diferents països i un sense grup control a un país distint amb 15 participants. Així, dels 38 participants que hi havia en una àrea, 18 feren la intervenció i, dels 36 participants de l'altra àrea, sols la feren 16 , la resta de participants pertanyia al grup control.

Pel que fa al gènere dels participants la tendència és clara, ja que la prevalença del TEA és més elevada en gènere masculí. Segons Boat i Wu (2015) de cada 4-5 persones que tenen el trastorn, solament 1 pertany al gènere femení. Per aquest motiu, resulta interessant conèixer la quantitat de xiques que han realitzat les intervencions analitzades. En primer lloc, es mencionen aquelles en què no ha participat cap xica, 18'18\% ( $n=4)$, Lacava et al. (2010), McHugh et al. (2010), Russo-Ponsaran et al. (2014) i Zhang et al. (2019). En segon lloc, els treballs que compten amb solament una, $22{ }^{\prime} 72 \%$ $(n=5)$ : Bauminger (2007), Lozano i Alcaraz (2011), Lozano i Alcaraz (2012), Chen et al. (2016) i Chen et al. (2015). Després, els treballs amb dos xiques, 13'63\% $(n=3)$, fan referència als de Lacava et al. (2007), Lopata et al. (2010) i Daniels et al. (2018). A continuació, els treballs que inclouen tres xiques $18 ' 18 \%(n=4)$, com ara a Ryan i Charragaín (2010), Rice et al. (2015), Fridenson-Hayo et al. (2017) i Zhang et al. (2019). Seguidament, s'agrupen els treballs de 5 xiques, excloent els de 4 perquè no consta cap, aquests són els de Hopkins et al. (2011), Russo-Ponsaran et al. (2015) i Thomeer et al. (2015), 13'63\% ( $n=3)$. Per últim, s'inclouen els articles de Williams et al. (2012) i Lopata et al. (2019) que compten amb més de 5 xiques, 9'09\% $(n=2)$. Amb aquestes dades s'arriba a la conclusió que el nombre de participants pertanyent al gènere femení se situa, sobretot, de zero a tres persones, $77^{\prime} 27 \%(n=17)$.

Posteriorment, s'han analitzat els articles per calcular el percentatge de xics de cadascuna de les intervencions i s'ha tret una mitjana tenint en compte la totalitat dels treballs. Aleshores, s'ha extret un $85^{\prime} 88 \%$ de xics participants enfront d'un $14^{\prime} 2 \%$ de xiques. Encara que s'ha de dir que en aquest càlcul s'ha exclòs el treball de Young i Posselt (2011) per no especificar el gènere de la mostra.

Amb relació a l'edat de la mostra, els articles es classifiquen seguint una franja d'edat homogènia o heterogènia. Per una banda, es troben els treballs de franja homogènia, 
$42 ' 85 \%(n=9)$, els participants dels quals tenen una diferència d'edat màxima de quatre anys, $1818 \%(n=1)$, com són les intervencions de McHugh et al. (2010) que solament introdueix participants de cinc anys, seguit dels tres anys de diferència, 9'09\% $(n=2)$, observats en els treballs de Zhang et al. (2019) i Chen et al. (2015) que van dels 3 a 6 anys i 11 a 13 anys respectivament $i$, finalment, una franja de quatre anys, 27 ' $27 \%(n=6)$, en els treballs de Lacava et al. (2007), que comprén dels 8 a 11 anys, Fridenson-Hayo et al. (2017) i Lopata et al. (2019), ambdós dels 6 als 9 anys, Chen et al. (2016) de 10 a 13 anys i, finalment, Golan et al. (2010) i Williams et al. (2012) amb membres de 4 a 7 anys.

Per altra banda, es troben els de franja heterogènia, 57'15\% $(n=12)$, que presenten una diferència de cinc fins a quinze anys entre els seus participants. En primer lloc, està el treball de Young i Posselt (2011), amb una mostra de 4 a 8 anys; el de Bauminger (2007) i Lacava et. al (2010) compren dels 7 als 11 anys. Per tant, la franja d'edat d'aquests tres articles se situa en cinc anys, $13^{\prime} 63 \%$. Seguidament, hi ha treballs amb sis anys de diferència, 18'18\% ( $n=4)$, com són els de Lozano i Alcaraz (2011), de 10 a 15 anys, Lozano i Alcaraz (2012), de 9 a 14 anys, Lopata et al. (2010) i Thomeer et al. (2015) de 7 a 12 anys. Amb una diferència de set anys, 9'09\% ( $n=2)$, es troben Russo-Ponsaran (2014) de 8 a 14 anys i Rice et al. (2015) de 5 a 11 anys. No hi ha cap intervenció amb una diferència de huit anys entre la mostra, per tant, el següent grup és el de nou anys, 9'09\% ( $n=2)$, que l'integren Russo-Ponsaran (2015), els membres del qual tenen entre 8 i 16 anys i Ryan i Charragaín (2010) de 6 a 14 anys. Finalment, hi ha un treball on els participants tenen una diferència de deu anys, des dels 6 fins als 15 anys en Hopkins et al. (2011), i una variació de quinze anys en Daniels et al. (2018), que oscil-la entre els 3 i 17 anys.

Tal com indica Lacava et al. (2010), es necessita certa maduresa per comprendre els programes emprats i saber utilitzar-los, per la qual cosa les intervencions no solen començar en edats primerenques. Per tant, s'ha vist reflectit que la majoria de les intervencions comencen a l'etapa intermèdia de l'Educació Primària, on és probable que el coeficient intel-lectual i la capacitat verbal siga major en comparació amb edats inferiors i, per tant, contribuïsca a millorar l'èxit de la intervenció.

Pel que fa a la metodologia de les intervencions, hi ha dos preferències clares: estudis de cas múltiple (50\%) i assaig controlat aleatoritzat (50\%). La primera és dona en Bauminger (2007), McHugh et al. (2010), Lacava et al. (2010), Lozano i Alcaraz (2011), Lozano i Alcaraz (2012), Chen et al. (2016), Chen et al. (2015) i Zhang et al. (2019). A més a més, hi ha 3 estudis pilots on també es fa aquest tipus d'intervenció (Lacava et al., 2007; Russo-Ponsaran et al., 2014; Daniels et al., 2018).

Per altra banda, molts treballs s'han centrat a realitzar assajos controlats aleatoris (Golan et al., 2010; Ryan i Charragaín, 2010; Lopata et al., 2010; Hopkins et al., 2011; Young i Posselt, 2011; Williams et al., 2012; Russo-Ponsaran et al., 2015; Rice et al., 2015; Thomeer et al., 2015; Lopata et al., 2019). Tanmateix, hi ha un treball en què es comparen els resultats d'una intervenció de dos tipus realitzada en tres països diferents, aquest és el de Fridenson-Hayo et al. (2017), que en un primer moment fan un estudi de cas múltiple en Regne Unit i posteriorment, en incloure millores en la intervenció, realitzaren dos assajos controlats aleatoris, un a Israel i altre a Suècia. Tal com diu Alcantud i Alonso (2019), aquelles intervencions que inclouen grup control ajuden a pal-liar la falta de generalització dels resultats que es produeixen en els estudis de cas, ja que com que no té grup control, no es pot garantir que aquests procedisquen solament de la intervenció. A més a més, el control que es té de les variables que s'analitzen és major quan es pot comparar amb altres individus que no estan rebent la intervenció. 
Seguidament, es procedeix a comentar els espais on es realitzen les intervencions. Aquests poden ser a l'entorn escolar, fora de l'escola en llocs destinats a aquestes finalitats o a casa. D'una banda, a l'escola es realitzen 11 intervencions (50\%), concretament els treballs de Bauminger (2007), Lozano i Alcaraz (2011), Lozano i Alcaraz (2012) i Lopata et al. (2019) que es fan a l'aula de referència de l'alumne junt amb el tutor. D'altra banda, Lacava et al. (2010), Ryan i Charragaín (2010), Hopkins et al. (2011), Russo-Ponsaran et al. (2014), Chen et al. (2014) i Chen et al. (2015) les realitzen en una sala de tractament de l'escola i Rice et al. (2015) en un laboratori d'aquesta. A més, fora de l'escola es realitzen 4 intervencions (18'18\%), Lopata et al. (2010) que les duen a terme en un campus universitari; Zhang et al. (2019) en un centre de rehabilitació, Russo-Ponsaran et al. (2015) en quatre sales situades en una clínica universitària, en una escola infantil o en una biblioteca i, per últim, Thomeer et al. (2015) en un laboratori. Seguidament, 7 dels treballs s'han dut a terme en la casa dels participants, dels quals un ha estat realitzat per terapeutes (McHugh et al. 2010) i els altres pels pares (Lacava et al., 2007; Golan et al., 2010; Young i Posselt, 2011; Williams et al., 2012; Fridenson-Hayo et al., 2017; Daniels et al., 2018). Per tant, encara que la majoria d'autors opten per fer les intervencions en l'entorn escolar o en espais destinats a aquests fins, s'observa que realitzar-les a casa també és una alternativa prou escollida (31'82\%).

Pel que fa als recursos utilitzats per abordar l'aprenentatge de les emocions, dels 22 estudis, 20 empren la tecnologia (90'9\%) aplicant programes destinats a millorar I'habilitat del reconeixement d'emocions a partir d'històries curtes, clips de vídeo, imatges d'expressions facials, etc. Aquests programes són: Aprende con Zapo, on s'usen fotos i relats amb dibuixos (Lozano i Alcaraz, 2011), Mix que disposa d'un entrenador virtual i es projecten clips de vídeo amb una coberta de pantalla per enfocar les parts en les quals el subjecte ha de focalitzar l'atenció (Russo-Ponsaran et al., 2014; Russo-Ponsaran et al., 2015), Emotiplay que compta amb quatre unitats didàctiques sobre les emocions on es treballa la veu, els trets facials, el llenguatge corporal i una combinació d'aquests mitjançant jocs motivacionals, recompenses i reforç positiu (Fridenson-Hayo et al. 2017), Qunatiandi que ofereix vídeos amb expressions facials il-lustrades en una tauleta electrònica (Zhang et al. 2019), The Transporters DVD que inclou episodis de vehicles amb rostres humans que expressen emocions i la seua explicació (Golan et al., 2010; Young i Posselt, 2011; Williams et al., 2012), GoogleGlass que són jocs per millorar el reconeixement d'emocions i la interacció social mitjançant retroalimentació visual i amb àudio (Daniels et al. 2018) i, l'ús de la tecnologia de realitat augmentada amb vídeo modelat (Chen et al. 2015) o automodelat (Chen et al. 2016) mitjançant la presentació d'històries socials quotidianes, a través d'una tauleta electrònica, on apareixen emocions que els participants han d'identificar.

D'altra banda, hi ha dos programes que utilitzen instrucció assistida i retroalimentació amb diferents zones d'aprenentatge on el xiquet pot trobar activitats per identificar, reconéixer, etiquetar i aprendre els trets facials de les emocions; com són: FaceSay (Hopkins et al., 2011; Rice et al., 2015) i MindReading (Bauminger, 2007; Lacava et al., 2007; Golan et al., 2010; Lacava et al., 2010). A més, Thomeer et al. (2015) combina l'ús de MindReading amb assaig de les habilitats en directe i reforç conductual. Seguidament, es mencionen els treballs en què no s'utilitza la tecnologia, 9'09\% $(n=2)$, com són el de Lopata et al. (2010) i Ryan i Charragaín (2010), ja que opten per instrucció directa i pràctica repetida com són els jocs de rol, dibuixos d'expressions, jocs per emparellar parts de la cara i identificar expressions en imatges i reconéixer-les en diferents situacions. Finalment, hi ha un treball en què es combina l'ús de materials didàctics, en format imprés i digital (Lozano i Alcaraz, 2012).

A continuació, s'especifiquen els tipus d'emocions ensenyades en cada treball, totes elles abordades mitjançant intervencions centrades en la perspectiva de la ToM. 
D'aquesta manera es troba que les emocions més repetides, i considerades com bàsiques segons la teoria de Ekman (1992), són: l'alegria, la tristesa, la ira, la por, la sorpresa i el fàstic. Sent l'alegria i la tristesa aquelles que s'han treballat en la totalitat dels articles. A continuació, la por i la ira, 90 '90\% $(n=20)$, que solament no s'han donat en Lopata et al. (2010) i en Zhang et al. (2019). Seguidament apareix la sorpresa, 45’45\% ( $n=10$ ) (Lacava et al., 2007; Lacava et al., 2010; Lozano i Alcaraz, 2011; Young i Posselt, 2011; Hopkins et al., 2011; Russo-Ponsaran et al., 2014; Chen et al., 2016; Chen et al., 2015; FridensonHayo et al., 2017; Lopata et al., 2019) i, per últim, el fàstic, 40’90\% ( $n=9$ ) (Lacava et al., 2010; Ryan i Charragaín, 2010; Rice et al., 2015; Chen et al., 2015; Russo-Ponsaran et al., 2015; Thomeer et al., 2015; Daniels et al., 2018; Lopata et al., 2019; Zhang et al., 2019).

Resulta important destacar que el nombre d'emocions donades de vegades depén del tipus de programa utilitzat, com és el cas de MindReading i The Transporters, ja que les emocions a treballar ja estan incorporades en els jocs, les activitats o els clips de vídeo que ofereixen. En primer lloc, MindReading inclou 15 emocions, les 6 bàsiques anomenades anteriorment i 9 de complexes: decebut, divertit, molest, avergonyit, gelós, amorós, nerviós, indecís i hostil (Bauminger, 2007; Lacava et al., 2007; Golan et al., 2010; Lacava et al., 2010). I, en segon lloc, The Transporters també n'inclou, a part de les 6 mencionades, 9 més: emocionat, cansat, hostil, amable, neutral, orgull, gelós, bromista i avergonyit (Golan et al., 2010; Young i Posselt, 2011; Williams et al., 2012). És necessari indicar que cap treball més ha arribat a incloure tantes emocions en una intervenció. No obstant això, la franja d'emocions que apareixen al llarg dels treballs és més ampla, però moltes d'elles es donen solament en un màxim de dos treballs, com per exemple: interés, avorriment i pensament en Lozano i Alcaraz (2011) i curiositat, avorriment, hilarant, ansiós i malalt en Zhang et al. (2019).

Amb relació als instruments de mesura emprats, gran part de les intervencions, $54{ }^{\prime} 54 \%$ $(n=12)$, comencen realitzant escales de valoració, emplenades per pares o mestres, per verificar el trastorn, saber la gravetat dels símptomes i avaluar conductes sobre el comportament social del xiquet. Aquestes són: BASC (Lopata et al., 2010; Thomeer et al., 2015), SCQ (Young i Posselt, 2011; Russo-Ponsaran et al., 2014; Russo- Ponsaran et al., 2015; Daniels et al., 2018), ADOS (Ryan i Charragaín 2010; Williams et al., 2012; Russo-Ponsaran et al., 2014; Russo-Ponsaran et al., 2015; Fridenson-Hayo et al., 2017), SRS-2 (Lopata et al., 2010; Rice et al., 2015; Thomeer et al., 2015; FridensonHayo et al., 2017; Daniels et al., 2018; Lopata et al., 2019), ADI-R (Golan et al., 2010; Thomeer et al., 2015; Russo-Ponsaran et al., 2015; Lopata et al., 2019). També hi ha altres que realitzen entrevistes als pares, 22'7\% $(n=5)$ (Lozano i Alcaraz, 2011; Lozano i Alcaraz, 2012; Chen et al., 2016; Chen et al., 2015; Daniels et al., 2018) o al docent (Lozano i Alcaraz, 2011; Lozano i Alcaraz, 2012).

A més, s'usen tests d'intel-ligència per a conèixer el coeficient intel-lectual del qual parteix el xiquet i si aquest és adequat per poder participar en la intervenció. La majoria utilitza l'Escala Wechsler d'Intel ·ligència, 54'54\% $(n=12)$, ja siga WASI (Russo-Ponsaran et al., 2014; Russo-Ponsaran et al., 2015), WISC-IV (Bauminger, 2007; Lopata et al., 2010; Young i Posselt 2011; Chen et al., 2016; Chen et al., 2015; Thomeer et al., 2015; Rice et al., 2015; Fridenson-Hayo et al., 2017; Lopata et al., 2019) o WPPSI-III (Young i Posselt, 2011; Williams et al., 2012). Ara bé, hi ha una xicoteta proporció d'autors, $13{ }^{\prime} 63 \%(n=3)$, que han utilitzat altres tests com KBIT (Hopkins et al., 2011; Lozano i Alcaraz, 2012) i ABIQ (Daniels et al., 2018).

Seguidament, i una vegada s'han realitzat les intervencions, es procedeix a fer proves per comprovar si s'han adquirit els objectius previstos. Com que els 22 articles van destinats a l'aprenentatge socioemocional, i concretament al reconeixement 
d'emocions, molts autors utilitzen els mateixos instruments per avaluar el que han aprés els participants. Els que més s'han repetit són: CAM-C (Lacava et al., 2007; Lacava et al., 2010; Thomeer et al., 2015; Lopata et al., 2019), NEPSY-II (Young i Posselt, 2011; Russo-Ponsaran et al., 2015; Rice et al., 2015), CATS (Golan et al., 2010; RussoPonsaran et al., 2014; RussoPonsaran et al., 2015), DANVA (Lopata et al., 2010; RussoPonsaran et al., 2014; RussoPonsaran et al., 2015) i ERT (Ryan i Charragaín, 2010; Hopkins et al., 2011). Tanmateix, hi ha treballs en què s'han avaluat les millores en el vocabulari emocional del subjecte, 9'09\% $(n=2)$, per a fer-ho s'han usat BPVS (Golan et al., 2010) i PPVT-R i Emotion Vocabulary Comprehension Test (Ryan i Charragaín, 2010).

Pel que fa a la durada de les intervencions, cal dir que aquesta és proporcional al nombre d'emocions ensenyades. Començant amb McHugh et al. (2010) que realitzen la intervenció la més curta, concretament 6 dies, englobant solament quatre emocions (alegria, tristesa, ira i por). Seguidament, es troben aquelles que van des de les 3 fins a les 6 setmanes, 36 '36\% $(n=8)$. Els treballs que pertanyen a aquesta franja són Young $i$ Posselt (2011), Chen et al. (2014) i Chen et al. (2015) amb 3 setmanes, seguits de Golan et al. (2010), Ryan i Charragaín (2010) i Williams et al. (2012) de quatre setmanes i Lopata et al. (2010) i Hopkins et al. (2011) de 6. No obstant això, s'ha de tindre en compte que les intervencions de Golan et al. (2010), Ryan i Charragaín (2010) i Young i Posselt (2011), inclouen fins a 15 emocions, ja que utilitzen The Transporters amb 15 capítols de 5 minuts en el que en cadascun d'ells es treballa una emoció. La resta dels treballs mencionats es limiten a donar les sis emocions bàsiques.

A continuació, apareixen les intervencions que tenen una durada de 2 o 3 mesos, que al tenir una durada més llarga engloben un nombre més elevat d'emocions. D'aquesta manera, amb 8 setmanes es troba Russo-Ponsaran et al. (2014), Russo-Ponsaran et al. (2015), Fridenson-Hayo et al. (2017) i Zhang et al. (2019). Seguit de les deu setmanes incloses en Lacava et al. (2007), Lacava et al. (2010), Lozano i Alcaraz (2011), Rice et al. (2015) i Lopata et al. (2019). Després, amb 11 setmanes Lozano i Alcaraz (2012) i, per últim, Thomeer et al. (2015) amb 12. Solament dos intervencions superen els 5 mesos, com són la de Daniels et al. (2010) amb 19 setmanes i Bauminger (2007) amb 28.

Per finalitzar s'anomenen els resultats obtinguts. Per una banda, el 86 '36\% $(n=19)$ dels estudis exposen millores en el dèficit analitzat gràcies a la intervenció, com són: la identificació, la comprensió i el reconeixement de les emocions (Lozano i Alcaraz, 2011; Hopkins et al., 2011; Chen et al., 2016; Chen et al., 2015; Zhang et al., 2019), solament el reconeixement de les emocions, 50\% ( $n=11)$, (Bauminger, 2007; Lacava et al., 2007; Lacava et al., 2010; Golan et al., 2010; Young i Posselt, 2011; Russo-Ponsaran et al., 2014; Russo-Ponsaran et al., 2015; Rice et al., 2015; Thomeer et al., 2015; FridensonHayo et al., 2017; Lopata et al., 2019) i l'etiquetatge d'emocions, 13'63\% ( $n=3)$ (Ryan i Charragaín, 2010; McHugh et al., 2010; Daniels et al., 2018). A més, Bauminger (2007) Lozano i Alcaraz (2011) i Hopkins et al. (2011) anuncien millores en la interacció social, front a Lacava et al. (2010), Rice et al. (2015) i Lopata et al. (2019) que manifesten que no és produïren. Finalment, és interessant mencionar que Lopata et al. (2010), Thomeer et al. (2015), Daniels et al. (2018) i Lopata et al. (2019) confirmen una disminució en els símptomes del TEA.

En els estudis on no es manifesten millores significatives, com són Lozano i Alcaraz (2012) i Williams et al. (2012), és pel fet que s'han realitzat en TEA de baix funcionament, ja que la resta intervencions s'han dut a terme amb alumnat TEA d'alt funcionament. Aquest evidencia que aquestes afavoreixen més a aquest tipus d'alumnat per posseir major coeficient intel-lectual i capacitat verbal. I, en el cas de Lopata et al. (2010) s'ha 
de dir que no hi ha bons resultats perquè és una intervenció de 6 setmanes que no solament treballa reconeixement d'emocions, dedicant a aquesta solament 6 sessions de 20 minuts cadascuna. És a dir, el baix efecte del tractament pot associar-se també amb una baixa intensitat d'aquest.

Per altra banda, hi ha estudis que incorporen fase de manteniment, 27'27\% ( $n=6$ ) (Golan et al., 2010; Ryan i Charragaín, 2010; Russo-Ponsaran et al., 2014; Chen et al., 2016; Chen et al., 2015; Zhang et al., 2019). Aquest fet és molt significatiu per veure si les millores perduren amb el temps i saber si realment la intervenció ha tingut l'efecte esperat o si, al contrari, l'alumnat ha aprés les tècniques per poder superar les tasques sense comprendre els conceptes que les engloben. No obstant això, la duració d'aquesta fase intervé en els resultats perquè no és el mateix realitzar una fase de manteniment després de dos setmanes d'haver realitzat la intervenció, com és el cas de Ryan i Charragaín (2010), Chen et al. (2016) i Zhang et al. (2019), que fer-la després de quatre setmanes, com seria en els altres casos, ja que com s'observa, els resultats són millors com menys temps ha passat.

S'han trobat algunes limitacions com ara l'heterogeneïtat de la mostra, l'extensió temporal de la intervenció, realitzar estudis amb xicoteta mostra que impedeixen la generalització dels resultats obtinguts, no disposar de grup control en certs treballs, el possible biaix del taxador en tindre en compte l'opinió de membres que han participat en la intervenció, la falta de mesures de seguiment a llarg termini i la realització de les intervencions per part dels pares, els quals poden deixar de ser objectius. A partir d'aquestes limitacions, com a proposta d'investigació futura, convindria desenvolupar intervencions en aquells alumnes compresos dins de la franja d'edat de l'atenció primerenca i obtenir uns resultats més ajustats a la realitat. A més a més, seria útil incrementar la duració dels estudis per verificar la seua efectivitat un temps després d'haver rebut el tractament. Per tant, és indiscutible la necessitat de continuar treballant en tots aquells aspectes que en aquesta anàlisi han quedat per esclarir.

Tanmateix, és convenient fer una menció especial a l'article de Hopkins et al. (2011) per ser el més complet i reunir la majoria de les variables analitzades que contribueixen a l'èxit de la intervenció. Aquest treball inclou dos grups control amb alumnat TEA d'alt i baix funcionament, la qual cosa permet veure la diferència i el grau de benefici que aporta la intervenció a cadascun dels grups depenent de les seues característiques. A més a més, el programa usat ensenya el reconeixement d'emocions d'una manera completa, incloent-hi els trets facials com l'expressió vocal i fent ús, per descomptat de la tecnologia.

Finalment, i de cara a una millora en la pràctica docent seria convenient tenir en compte l'opinió de les famílies i de la resta de la comunitat educativa que treballen amb l'alumne/a i, per altra banda, les característiques de la mostra (sexe, edat, coeficient intel-lectual i capacitat cognitiva), el nombre d'emocions junt amb el temps del qual disposem i els recursos més apropiats segons les característiques l'alumne, ja que s'ha demostrat que els que han utilitzat una tauleta electrònica o un ordinador junt amb els clips de vídeo explicatius de les emocions i exercicis de pràctica han obtingut millors resultats (Russo-Ponsaran et al., 2014; Russo-Ponsaran et al., 2015; Fridenson-Hayo et al., 2017; Zhang et al., 2019; Young i Posselt, 2011; Golan et al., 2010; Williams et al., 2012; Daniels et al., 2018; Rice et al., 2015; Hopkins et al., 2011; Lacava et al., 2007; Golan et al., 2010; Lacava et al., 2010; Bauminger, 2007; Thomeer et al., 2015). A més, valorant la càrrega cognitiva de cadascun dels programes analitzats als articles, caldria utilitzar The Transporters per al primer cicle d'Educació Primària, FaceSay per al segon cicle i MindReading per al tercer. No obstant això s'hauria analitzar detalladament el cas per saber què seria el més convenient per a cada alumne/a. 


\section{Referències}

Alcantud Marín, F., Alonso Esteban, i Mata Iturralde, S. (2018). Prevalencia de los trastornos del espectro autista: revisión de datos.

Alcantud Marín, F. i Alonso Esteban, Y. (2019) Trastornos del Espectro del Autismo: Manual de Intervención Psico-educativa. Universitat de València. Apunts de classe facilitats pel professor.

Bauminger, N. (2007). Brief Report: Individual Social-Multi-Modal Intervention for HFASD. J Autism Dev Disord, 37, 1593-1604.

Chen, C., Lee, I., i Lin, L. (2015). Augmentd reality-based self-facial modeling to promote the emotional expression and social skills of adolescents with autism spectrum disorders. Research in Developmental Disabilities, 36, 396-403.

Chen, C., Lee, I., \& Lin, L. (2016). Augmented reality-based video-modeling storybook of nonverbal facial cues for children with autism spectrum disorder to improve their perceptions and judgments of facial expressions and emotions. Computers in Human Behavior, 55, 477-485.

Cuxart, F., Ballabriga, J., \& del Claustre, M. (1998). Evolución conceptual del termino 'autismo': una perspectiva histórica. Revista de Historia de la Psicología., 19(2-3), 0369-389.

Daniels, J., Schwartz, J. N., Voss, C., Haber, N., Fazel, A., Kline, A., Washington, P., Feinstein, C., Winograd, T., \& Wall, D. P. (2018). Exploratory study examining the at-home feasibility of a wearable tool for social-affective learning in children with autism. Npj Digital Medicine, 1, 32.

Fridenson-Hayo, S., Berggren, S., Lassalle, A., Tal, S., Pigat, D., Meir-Goren, N., O'Reilly, H., Ben-Zur, S., Bölte, S., Baron-Cohen, S., \& Golan, O. (2017). 'Emotiplay': a serious game for learning about emotions in children with autism: results of a cross-cultural evaluation. Eur Child Adolesc Psychiatry, 26, 979-992.

Golan, O., Ashwin, E., Granader, Y., McClintock, S., Day, K., Leggett, V., \& BaronCohen, S. (2010). Enhancing Emotion Recognition in Children with Autism Spectrum Conditions: An Intervention Using Animated Vehicles with Real Emotional Faces. $J$ Autism Dev Disord, 40, 269-279.

Hopkins, I., Gower, T., Perez, T., Smith, D., Amthor, F., Wimsatt F., \& Biasini, F. (2011). Avatar Assistant: Improving Social Skills in Students with an ASD Through a Computer-Based Intervention. J Autism Dev Disord, 41, 1543-1555.

Lacava, P., Golan, O., Baron-Cohen, S., \& Smith, M. (2007). Using Assistive Technology to Teach Emotion Recognition to Students with Asperger Syndrome. Remedial and special education, 28(3), 174-181.

Lacava, P., Rankin, A., Mahlios, E., Cook, K., \& Simpson, R. (2010). A single case design evaluation of a software and tutor intervention addressing emotion recognition and social interaction in four boys with ASD. Autism, 14(3), 161-178.

Lopata, C., Thomeer, M., Volker, M., Toomey, J., Nida, R., Lee, G., Smerbeck, A., \& Rodgers, J. (2010). RCT of a Manualized Social Treatment for High-Functioning Autism Spectrum Disorders. J Autism Dev Disord, 40, 1297-1310. 
Lopata, C., Thomeer, M., Rodgers, J., Donnelly, J., McDonald, C., Volker, M., Smith, T., \& Wang, H. (2019) Cluster Randomized Trial of a School Intervention for Children with Autism Spectrum Disorder. Journal of Clinical Child \& Adolescent Psychology, 48(6), 922-933.

Lozano, J. i Alcaraz, S. (2011). Software educativo para la enseñanza de competencias emocionales en alumnado con trastornos del espectro autista, Educación $X X 1$, 14(2), 189-212.

Lozano, J. i Alcaraz, S. (2012). Enseñanza de emociones y creencias en alumnos con trastornos del espectro autista: efectos sobre las habilidades sociales cotidianas. Revista de Educación, 358, 357-381.

McHugh, L., Bobarnac, A., \& Reed, P. (2010). Brief Report: Teaching Situation-Based Emotions to Children with Autistic Spectrum Disorder. J Autism Dev Disord, 41, 1423-1428.

Rice, L., Wall, C., Fogel, A., \& Shic, F. (2015). Computer-Assisted Face Processing Instruction Improves Emotion Recognition, Mentalizing, and Social Skills in Students with ASD. J Autism Dev Disord, 45, 2176-2186.

Rivière, Á. (2005). Autismo: Orientaciones para la intervención educativa. Madrid: Trotta.

Russo-Ponsaran, N., Evans-Smith, B., Johnson, J., \& McKown, C. (2014). A Pilot Study Assessing the Feasibility of a Facial Emotion Training Paradigm for School-Age Children with Autism Spectrum Disorders. Journal of Mental Health Research in Intellectual Disabilities, 7(2), 169-190.

Russo-Ponsaran, N., Evans-Smith, B., Johnson, J., Russo, J., \& McKown, C. (2015). Efficacy of a Facial Emotion Training Program for Children and Adolescents with Autism Spectrum Disorders. J Nonverbal Behav, 40, 13-38.

Ryan, C., \& Charragaín., C. (2010). Teaching Emotion Recognition Skills to Children with Autism. J Autism Dev Disord, 40, 1505-151.

Sevilla, M. D. S. F., Bermúdez, M. O. E., \& Sánchez, J. J. C. (2013). ¿Cuántas personas con autismo hay? Una revisión teórica. International Journal of Developmental and Educational Psychology, 1(1), 769-786.

Thomeer, M., Smith, R., Lopata, C., Volker, M., Lipinski, A., Rodgers, C., \& Lee., G. (2015). Randomized Controlled Trial of Mind Reading and In Vivo Rehearsal for High-Functioning Children with ASD. J Autism Dev Disord, 45, 2115-2127.

Williams, B., Gray, K., \& Tonge, B. (2012). Teaching emotion recognition skills to young children with autism: a randomised controlled trial of an emotion training programme. Journal of Child Psychology and Psychiatry, 53(12), 1268-1276.

Young, R., \& Posselt, M. (2011). Using the Transporters DVD as a Learning Tool for Children with Autism Spectrum Disorders (ASD). J Autism Dev Disord, 42, 984-991.

Zhang, S., Xia, X., Li, S., Shen, L., Liu, J., Zhao, L., \& Chen, C. (2019) Using technologybased learning tool to train facial expression recognition and emotion understanding skills of Chinese pre-schoolers with autism spectrum disorder. International Journal of Developmental Disabilities, 65(5), 378-386. 